\title{
Cardiac involvement in congenital myotonic dystrophy
}

Håkan Forsberg, Bert-Ove Olofsson, Anders Eriksson, Staffan Andersson

\begin{abstract}
Seven young patients (mean age 19 years 8 months) with congenital myotonic dystrophy and with defined symptoms at birth were investigated by electrocardiography and echocardiography. None had cardiovascular symptoms. Electrocardiograms or echocardiograms or both were abnormal in all patients. Atrioventricular and intraventricular conduction defects were the most common electrocardiographic abnormalities and were seen in five patients. The echocardiographic examinations showed impaired left ventricular systolic function in one patient. Other echocardiographic findings were a small left ventricle and atrium, minor valve defects, and mitral valve prolapse.

This study shows that the heart is often affected in young patients with congenital myotonic dystrophy. The specialised conduction system is often affected and so too is the myocardium, causing impaired systolic function.
\end{abstract}

Myotonic dystrophy is a multisystem disease that is inherited in an autosomal dominant fashion at a locus on chromosome 19. ${ }^{1}$ The disease is characterised by variable expression and severity, and symptoms usually appear when the patient is between 20 and 50 years old. ${ }^{2}$ In adults the heart is often affected, ${ }^{3}$ and the high incidence of sudden unexpected death, probably owing to arrhythmias or high degree atrioventricular block, is a major unsolved clinical problem in this disease. ${ }^{45}$ Electrocardiographic and echocardiographic studies showed that the heart disease is progressive and that its severity corresponds to the severity of the neuromuscular disability. ${ }^{6-8}$

The term congenital myotonic dystrophy is applied to a subgroup of patients who have severe symptoms at birth. Newborn patients have respiratory and feeding problems, muscular hypotonia, and arthrogryphosis. Neonatal mortality is high. In surviving children a severe form of myotonic dystrophy develops with both neuromuscular and intellectual disability. ${ }^{10}$ The genetic defect in congenital myotonic dystrophy is inherited via the mother and the possibility of non-mendelian cytoplasmic transmission was suggested. ${ }^{112}$

We used electrocardiography and echocardiography to assess the extent to which the heart was affected in young patients with congenital myotonic dystrophy.

\section{Patients and methods}

We studied seven young patients with congenital myotonic dystrophy who fulfilled the diagnostic criteria of Volpe during the newborn period. ${ }^{9}$ Table 1 shows some of the neonatal features in the patients. We studied all surviving patients with congenital myotonic dystrophy who had been diagnosed since 1970 at the Department of Paediatrics, Central Hospital, Boden, Sweden. This department serves the coastal region of Norrbotten, the northernmost province of Sweden, with 95000 inhabitants and an exceptionally high prevalence of myotonic dystrophy. ${ }^{7}$ The mean age of the patients was $19 \cdot 7$ years (range 11-27 years). Table 1 presents some additional clinical characteristics of the patients. There were two pairs of siblings (patients 2 and 3 and 6 and 7). Most patients were thinner than normal, and only one had a body mass index of $>20 \mathrm{~kg} / \mathrm{m}^{2}$. Six patients had a straight or scoliotic thoracic spine and a short anteroposterior thoracic diameter.

The severity of the neuromuscular disability was classified on the basis of the patient's ability to perform those daily activities that can be limited by neuromuscular symptoms: mild, subjective symptoms but no functional disturbances; moderate, functional disturbances but the patient is able to undertake all activities of daily life and is able to do a light job; severe, major functional disturbances with the patient being incapable of undertaking most daily activities. Intellectual disability was classified according to the patient's ability to read ordinary texts: mild, minor reading difficulties; moderate, pronounced reading difficulties; severe, the patient was unable to read. The severity of neuromuscular disability was classified as mild in one, moderate in five, and severe in one of the patients; and the intellectual disability was classified as moderate in three and severe in four of the patients. None of the patients had any symptoms attributable to heart dysfunction or was taking medication known to induce electrocardiographic or echocardiographic changes. All patients had a normal blood pressure.

A 12 lead electrocardiogram (I, II, III, aVR, aVL, aVF, V1-V6) was recorded at a paper speed of $50 \mathrm{~mm} / \mathrm{s}$. The evaluation included a classification according to the Minnesota code ${ }^{13}$ of arrhythmias, $P$ wave amplitude, atrioventricular and intraventricular conduction defects, $Q$ and QS patterns, hypertrophy patterns, $S T$ elevation/depression, and $T$ wave features. We used the criteria of Castellanos and Lemberg for fascicular blocks. ${ }^{14} \mathrm{~A} \mathrm{P}$ wave 
Table 1 Clinical characteristics of seven patients with congenital myotonic dystrophy

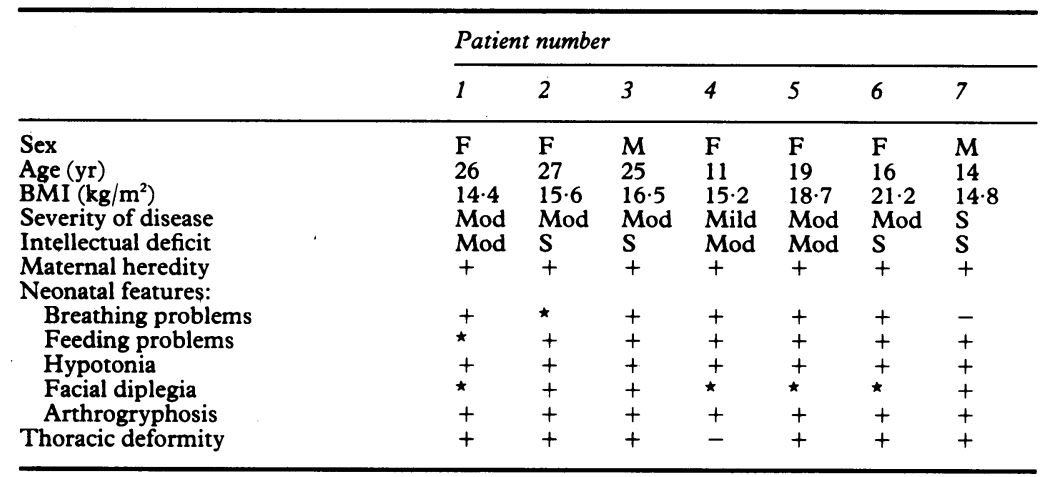

BMI, body mass index, Mod, moderate; S, severe; `data not available.

of $>0.13 \mathrm{~mm}$ was defined as broadened. The QT interval was corrected for differences in heart rate by a modification of Bazett's formula $(\mathrm{QTc}=\mathrm{QT} / \sqrt{ } \mathrm{RR}$, where the $\mathrm{QTc}$ interval is the corrected value of the $Q T$ interval and $R R$ is the cardiac cycle length. ${ }^{15}$

An ATL Ultramark 8 sonograph (Advanced Technology Laboratories, Bothell, Washington, USA) was used for $M$ mode, cross sectional, and Doppler echocardiography. The patients were examined lying on their left side and back while breathing quietly, and traces were obtained with the transducers in the parasternal, apical, and subcostal positions. $M$ mode measurements were performed in accordance with the standards of the American Society of Echocardiography, ${ }^{16}$ and the values obtained were compared with normal values presented by Henry et al. ${ }^{17}$ Left ventricular systolic function was measured as fractional shortening (left ventricular end diastolic diameter minus left ventricular end systolic

Table 2 Electrocardiographic findings in seven patients with congenital myotonic dystrophy

\begin{tabular}{|c|c|c|c|c|c|c|c|}
\hline & \multicolumn{7}{|c|}{ Patient number } \\
\hline & 1 & 2 & 3 & 4 & 5 & 6 & 7 \\
\hline Sinus rhythm & + & + & + & + & + & + & + \\
\hline Extrasystoles & - & - & - & - & - & + & - \\
\hline Heart rate (beats $/ \mathrm{min}$ ) & 86 & 57 & 68 & 94 & 77 & 77 & 78 \\
\hline$P$ wave & $\mathbf{N}$ & $\mathrm{N}$ & $\mathbf{N}$ & $\mathrm{N}$ & $\mathrm{N}$ & $\mathbf{N}$ & $\mathbf{N}$ \\
\hline First degree AV block & + & + & + & - & - & + & + \\
\hline $\mathrm{PQ}$ interval (s) & 0.20 & 0.22 & $0 \cdot 24$ & $0 \cdot 16$ & $0 \cdot 18$ & $0 \cdot 20$ & $0 \cdot 21$ \\
\hline IV block & LBBB & LAFB & LAFB & - & LAFB & - & LPFB \\
\hline QRS interval & $0 \cdot 13$ & $0 \cdot 11$ & $0 \cdot 10$ & 0.08 & 0.08 & 0.09 & 0.09 \\
\hline QT interval (s) & 0.37 & 0.42 & $0 \cdot 40$ & $0 \cdot 30$ & 0.34 & 0.39 & 0.37 \\
\hline QTc interval (s) & 0.44 & 0.41 & 0.43 & $0 \cdot 38$ & 0.38 & 0.44 & 0.42 \\
\hline Twave & $\mathrm{N}$ & $\mathrm{N}$ & $\mathrm{N}$ & $\mathrm{N}$ & $\mathrm{N}$ & $\mathbf{N}$ & $\mathrm{N}$ \\
\hline QRS axis (degrees) & \pm 0 & -40 & -45 & +90 & -40 & +80 & +135 \\
\hline ST deviation & - & - & - & - & - & - & - \\
\hline
\end{tabular}

$\mathrm{N}$, normal; AV, atrioventricular; IV, intraventricular; LBBB, left bundle branch block; LAFB, left anterior fascicular block; LPFB, left posterior fascicular block.

Table 3 Echocardiographic findings in seven patients with congenital myotonic dystrophy (abnormal results are underlined)

\begin{tabular}{|c|c|c|c|c|c|c|c|}
\hline & \multicolumn{7}{|c|}{ Patient number } \\
\hline & 1 & 2 & 3 & 4 & 5 & 6 & 7 \\
\hline $\begin{array}{l}\text { Aortic diameter (mm) } \\
\text { Left atrial diameter (mm) } \\
\text { LVD(D) (mm) } \\
\text { LVD(S) (mm) } \\
\text { IVS (mm) } \\
\text { PWT (mm) } \\
\text { Fractional shortening }(\%) \\
\text { Normal right ventricle } \\
\text { Valve abnormality } \\
\text { Hyperrefractile myocardial echoes }\end{array}$ & $\begin{array}{l}25 \\
28 \\
40 \\
28 \\
8 \\
8 \\
30 \\
+ \\
\text { MR } \\
-\end{array}$ & $\begin{array}{l}22 \\
28 \\
40 \\
28 \\
10 \\
9 \\
30 \\
+ \\
\text { MVP } \\
-\end{array}$ & $\begin{array}{l}24 \\
\frac{27}{38} \\
\frac{22}{11} \\
11 \\
42 \\
+ \\
\text { TR } \\
-\end{array}$ & $\begin{array}{r}18 \\
30 \\
33 \\
23 \\
7 \\
7 \\
30 \\
+ \\
- \\
-\end{array}$ & $\begin{array}{r}22 \\
29 \\
\frac{32}{21} \\
\frac{21}{8} \\
8 \\
34 \\
+ \\
- \\
-\end{array}$ & $\begin{array}{r}20 \\
21 \\
41 \\
28 \\
9 \\
10 \\
32 \\
+ \\
- \\
-\end{array}$ & $\begin{array}{r}19 \\
27 \\
39 \\
29 \\
9 \\
8 \\
26 \\
+ \\
- \\
-\end{array}$ \\
\hline
\end{tabular}
LVD(D), left ventricular end diastolic diameter; $L V D(S)$, left ventricular systolic diameter;
IVS, interventricular septal thickness; PWT, left ventricular posterior wall thickness; MR, mitral regurgitation; TR, tricuspid regurgitation; MVP, mitral valve prolapse. diameter divided by left ventricular end diastolic diameter). Right ventricular dimensions and systolic function were subjectively estimated as normal or abnormal. Mitral valve prolapse was diagnosed when the criteria of Devereux et $a l^{18}$ were fulfilled. We defined hyperrefractile myocardial echoes as strongly refractile myocardial echoes persisting in different projections or angulations at gain settings low enough to eliminate completely the echoes from the surrounding endocardium and myocardium. ${ }^{19}$

\section{Results}

Table 2 shows the electrocardiographic findings. Six patients had abnormal electrocardiograms with atrioventricular or intraventricular conduction defects or both. First degree atrioventricular block was found in five, left anterior fascicular block in three, left bundle branch block in one, and left posterior fascicular block in one of the patients. There were combined atrioventricular and intraventricular conduction defects in four electrocardiograms. All patients had normal sinus rhythm; one had solitary supraventricular extrasystoles. Hypertrophy patterns, abnormal $\mathrm{Q}$ waves, prolonged QT intervals, or ST-T changes were not found.

Table 3 shows the echocardiographic findings. The echocardiograms were abnormal in all patients. The left ventricular end diastolic diameter was shorter than normal in three patients, and two of these also had a short left ventricular end systolic diameter. One of the patients showed decreased fractional shortening with normal left ventricular dimensions and no local hypokinesia. One echocardiogram fulfilled the criteria of mitral valve prolapse. Doppler echocardiography showed mitral regurgitation in one and tricuspid regurgitation in another of the patients. These regurgitations were minor, but in both cases sufficiently large to be classified as abnormal by the investigator. The patients with mitral valve abnormalities had normal left ventricular dimensions and fractional shortening, and the patient with tricuspid regurgitation had no signs of right ventricular abnormalities. None of the patients had wall hypertrophy, ventricular dilatation, pericardial effusions, or abnormal myocardial texture.

\section{Discussion}

Congenital myotonic dystrophy is a rare disorder. O'Brien and Harper estimated the prevalence as 1 per 100000 inhabitants in Wales, ${ }^{20}$ and Wesström et al reported an incidence of 1 per 3350 live births in Sweden. ${ }^{21}$ Our seven patients live in a region with 95000 inhabitants and an exceptionally high prevalence of myotonic dystrophy. ${ }^{7}$ A high regional prevalence is a prerequisite of systematic studies; this may explain why the effect of congenital myotonic dystrophy on the heart has not been studied before. The absence of young children in our series is probably the result of genetic counselling during the past decades. 
Our knowledge of the prevalence and features of the heart disease associated with myotonic dystrophy is based on electrocardiographic and echocardiographic studies of patients in whom symptoms generally started in adulthood. Occasional patients with congenital disease are probably included in these series, but usually these cannot be identified from patient data. Electrocardiographic abnormalities were reported in most patients with myotonic dystrophy. ${ }^{3}$ We found, in a recent study, abnormal electrocardiograms in $63 \%$ of all patients and in $96 \%$ of those with severe neuromuscular disability. ${ }^{7}$ Atrioventricular and intraventricular conduction defects were the most common abnormalities but atrial fibrillation, abnormal $Q$ waves, and repolarisation abnormalities were found in patients with severe neuromuscular disability. Echocardiographic and radionuclide studies have shown that the myocardium is affected in some patients with myotonic dystrophy, causing ventricular wall hypertrophy, left ventricular dilatation, and reduced fractional shortening. ${ }^{3722}$ In another echocardiographic study of another 30 adult patients we found left ventricular dilatation in six $(20 \%)$, decreased left ventricular systolic function in five $(17 \%)$, and left ventricular hypertrophy in four $(13 \%){ }^{8}$ The frequency and severity of electrocardiographic and echocardiographic abnormalities increased with the increasing severity of neuromuscular disability. ${ }^{78}$

In this study we found electrocardiographic abnormalities in six out of seven patients with congenital myotonic dystrophy. The main electrocardiographic finding, a high prevalence of atrioventricular and intraventricular conduction defects, accords with previous findings in patients with onset of symptoms in adulthood. No electrocardiogram in this series showed atrial fibrillation, abnormal $Q$ waves, or repolarisation abnormalities-all signs of myotonic dystrophy that occur in adults with severe myotonic dystrophy. ${ }^{7}$ We found echocardiographic abnormalities in all seven patients. Myocardial involvement with decreased left ventricular systolic function was, however, found in only one of the patients. No echocardiogram showed left ventricular hypertrophy or left ventricular dilatation. The clinical significance of some of these echocardiographic changes such as subnormal left ventricular and atrial dimensions and minor valve regurgitation without other signs of heart dysfunction is unclear. Subnormal body mass indices and thoracic deformities may have contributed to these findings. Several groups have reported an increased prevalence of mitral valve prolapse in patients with myotonic dystrophy, ${ }^{23}$ but we did not find any clear overrepresentation of this anomaly in our study. A putative causal association between myotonic dystrophy and mitral valve prolapse was also questioned because myxomatous degeneration of the mitral valve or localised myocardial dysfunction have not been reported in myotonic dystrophy. ${ }^{525}$

We found signs of electrocardiographic or echocardiographic signs of heart involvement in all the patients with congenital myotonic dystrophy that we examined. Conduction defects were the main electrocardiographic finding. There were signs of impaired left ventricular function in one of the patients. The course and clinical implications of these features remain to be investigated.

1 Wieringa B, Brunner H, Hulsebos T, Schonk D, Ropers HH. Genetic and physical demarcation of the locus for dystrophia myotonica. Adv Neurol 1988;48:47-69.

2 Harper PS. Myotonic dystrophy. Philadelphia: WB Saunders, 1979.

3 Moorman JR, Coleman RE, Packer DL, et al. Cardiac involvement in myotonic muscular dystrophy. Medicine 1985;64:371-87.

4 Grigg LE, Chan W, Mond HG, Vohra JK, Downey WF. Ventricular tachycardia and sudden death in myotonic dystrophy: clinical, electrophysiologic and pathologic features. J Am Coll Cardiol 1985;6:254-6.

5 Perloff JK, Stevenson WG, Roberts NK, Cabeen W, Weiss $\mathrm{J}$. Cardiac involvement in myotonic muscular dystrophy (Steinert's disease): a prospective study of 25 patients. $\mathrm{Am}$ (Steinert's disease): a prospect

6 Melacini P, Buja G, Fasoli G, et al. The natural history of cardiac involvement in myotonic dystrophy: an eight-yea follow-up in 17 patients. Clin Cardiol 1988;11:231-8.

7 Olofsson B-O, Forsberg H, Andersson S, Bjerle P, Henriksson A, Wedin I. Electrocardiographic findings in myotonic dystrophy. Br Heart J 1988;59:47-52.

8 Forsberg H, Olofsson BO, Andersson S, Backman C, Henriksson A. Echocardiographic features of myotonic dystrophy. Am J Noninv Cardiol (in press).

9 Volpe J. Neurology of the newborn. Philadelphia: WB Saunders, 1987.

10 Vanier TM. Dystrophia myotonica in childhood. Br Med J 1960;i:1284-8.

1 Dodge PR, Gamstorp I, Byers RK, Russel P. Myotonic dystrophy in infancy and childhood. Pediatrics 1965;35: 3-19.

12 Harper PS. Congenital myotonic dystrophy in Britain. I. Clinical aspects. Arch Dis Child 1975;50:505-13.

13 Prineas RJ, Crow RS, Blackburn H. The Minnesota manual code of electrocardiographic findings. Standards and procedures for measurement and classification. Boston: John procedures for mea

14 Castellanos A Jr, Lemberg L. Diagnosis of isolated and Castellanos A Jr, Lemberg $\mathrm{L}$. Diagnosis of isolated and
combined block in the bundle branches and the divisions combined block in the bundle branches and the

15 Ahnve S. Correction of the QT interval for heart rate. Review of different formulas and the use of Bazett's formula in myocardial infarction. Am Heart $J 1985$ 109:568-74.

6 Sahn DJ, de Maria A, Kisslo J, Weyman A. Recommendations regarding quantification in $M$-mode echocardiography: results of a survey of echocardiographic measurements. Circulation 1978;58:1073-83.

17 Henry WL, Gardin JM, Ware JH. Echocardiographic measurements in normal subjects from infancy to old age. Circulation 1980;62:1054-60

18 Devereux RB, Kramer-Fox R, Shear MK, Kligfield P, Pini R, Savage DD. Diagnosis and classification of severity of mitral valve prolapse: methodologic, biologic, and prognostic considerations. Am Heart J 1987;113: and progn

19 Bhandari AK, Nanda NC, Myocardial texture characterisation by two-dimensional echocardiography. Am J Cardiol tion by two-dimens

20 O'Brien TA, Harper PS. Course, prognosis and complications of childhood-onset myotonic dystrophy. Dev Med Child Neurol 1984;26:62-7.

21 Wesström G, Bensch J, Schollin J. Congenital myotonic dystrophy. Acta Paediatr Scand 1986;75:849-54

22 Reeves WC, Griggs R, Nanda NC, Thomson K, Gramia KR. Echocardiographic evaluation of cardiac abnormalities in Duchenne's dystrophy and myotonic muscular dystrophy. Arch Neurol 1980;37:273-7.

23 Streib EW, Meyers DG, Sun SF. Mitral valve prolapse in myotonic dystrophy. Muscle Nerve 1985;8:650-3.

24 Winters SJ, Schreiner B, Griggs RC, Rowley P, Nanda NC Familial mitral valve prolapse and myotonic dystrophy. Ann Intern Med 1976;85:19-22.

25 Malcolm AD. Mitral valve prolapse associated with other disorders. Casual coincidence, common link, or fundamental genetic disturbance? Br Heart J 1985;53:353-62. 